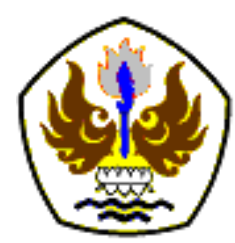

INFOMATEK

Volume 21 Nomor 2 Desember 2019

\title{
PEMETAAN KEBISINGAN DI RUANG DEPARTEMEN SPARE PART DAN DEPARTEMEN LAS MENGGUNAKAN APLIKASI SURFER
}

\author{
Lili Mulyatna, Yonik Meilawati Yustiani ${ }^{*}$, Ari Rizky Darmawan \\ Program Studi Teknik Lingkungan \\ Fakultas Teknik - Universitas Pasundan
}

\begin{abstract}
Abstrak: PT. SA adalah industri penyedia suku cadang (spare part) dan rekayasa mesin produksi. Proses produksi pabrik ini berpotensi menimbulkan kebisingan yang dapat menurunkan tingkat kenyamanan bahkan kesehatan responden yang berada di sekitarnya. Penelitian ini bertujuan untuk mengukur tingkat kebisingan yang terjadi di ruang Departemen Spare Part dan Departemen Las industri tersebut. Pemetaan dilakukan dari hasil pengukuran ini. Dengan pemetaan yang diperoleh, maka penanggulangan dapat dilakukan sesuai dengan lokasi yang telah terpetakan memiliki kebisingan melewati baku mutu. Pengukuran tingkat kebisingan dilakukan dengan menggunakan alat Sound Level Meter. Pengukuran dilakukan berdasarkan SNI 7231:2009, yaitu selama 10 menit pada setiap titik dan data yang diperoleh adalah data tingkat kebisingan. Pembuatan peta kebisingan dalam ruang Spare Part dan Las tersebut dilakukan aplikasi Surfer versi 11. Pengukuran menunjukkan bahwa tingkat kebisingan yang tertinggi terjadi pada unit Departemen Spare Part. Nilai kebisingan yang terjadi yaitu 95,4 dB. Sedangkan pada Departemen Las mempunyai tingkat kebisingan terendah sebesar 90,9 dB. Beberapa faktor lain di luar suara mesin juga mempengaruhi kebisingan, baik berasal dari alat transportasi, suara manusia dan aktivitas penyelesaian barang menggunakan alat pemukul.
\end{abstract}

Kata kunci: Industri Suku Cadang, Kebisingan, Pemetaan

\section{PENDAHULUAN}

Kebisingan merupakan gelombang suara yang berada pada tingkat mengganggu, sehingga menjadi suara yang tidak dikehendaki (Wahyuni dkk. [1]). Kegiatan industri berpotensi menimbulkan kebisingan, terutama pabrik pembuat peralatan yang dalam prosesnya melibatkan kerja mesin (Khairai dkk. [2]). Kebisingan dapat mengakibatkan

*)yonik@unpas.ac.id

Pertama diterima : 19 Agustus 2019

Direvisi :14 Oktober 2019

Disetujui untuk publikasi: 14 Oktober 2019 bahaya kesehatan, yaitu menurunkan tingkat ambang pendengaran, terutama bagi orang yang terpapar bising dengan jangka waktu yang lama (Mohammadizadeh dkk. [3]). Oleh sebab itu, kebisingan perlu dikendalikan dengan baik (Mulyatna dkk. [4]).

Roda gerinda, merupakan salah satu mesin yang sering digunakan dalam industri pembuatan suku cadang kendaraan. Mesin gerinda ini menimbulkan bising yang relatif mengganggu tergantung pada ukuran rodanya 
(Zulfiar [5]). Nilai kebisingan pada industri spare part dapat mencapai hingga 92,3 dBA (Setyaningrum [6]).

PT. SA adalah sebuah industri yang membuat suku cadang untuk kendaraan berupa gigi serta alat-alat produksi sesuai pesanan. Dalam proses produksinya, PT. SA menggunakan berbagai mesin, termasuk gerinda dan las yang menimbulkan bising dan berpotensi menurunkan kesehatan pekerjanya. Potensi bahaya ini menjadikan industri melakukan tindakan pencegahan dan pengobatan terhadap gangguan pendengaran akibat kebisingan tersebut. Agar dapat dilakukan langkah-langkah pencegahan, perlu pemetaan terlebih dahulu kondisi kebisingan yang terjadi.

Ruangan yang memiliki risiko tinggi terpapar kebisingan di PT. SA adalah Departemen Spare Part dan Departemen Las. Untuk merancang perangkat pencegahan dan pengendalian bising pada departemen tersebut, maka penelitian ini dilakukan. Penelitian ini betujuan untuk memetakan kondisi kebisingan yang terjadi di Departemen Spare Part dan Departemen Las sebagai rekomendasi perumusan upaya penanggulangan kebisingan di PT. SA.

\section{METODOLOGI}

Metodologi yang digunakan dalam pelaksanaan penelitian ini adalah seperti pada Gambar 1.

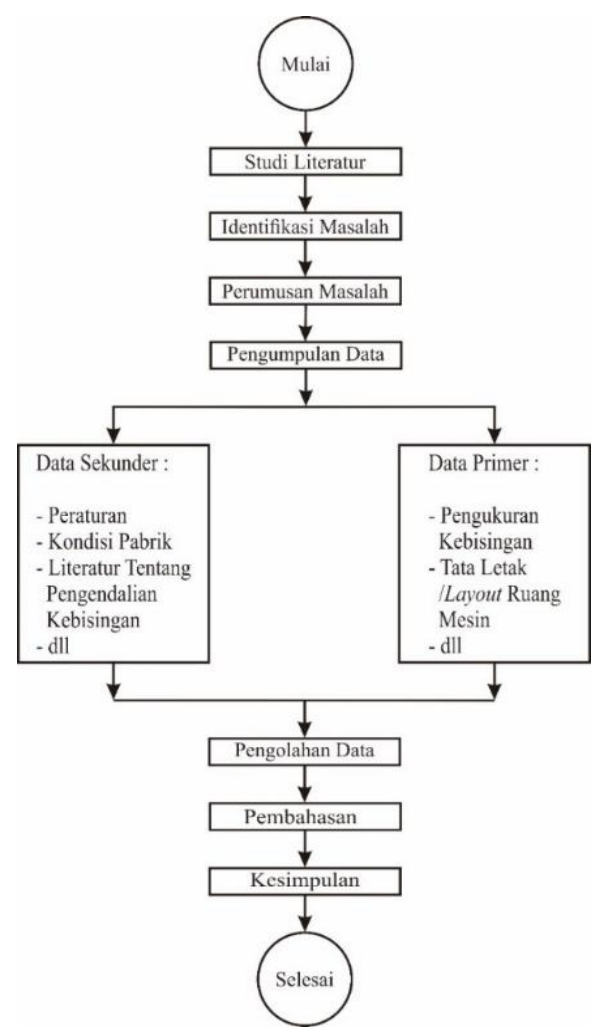

Gambar 1.

Diagram Alir Tahapan Penelitian

\subsection{Pengumpulan Data}

Pengumpulan data dilakukan untuk membantu jalannya penelitian. Dalam memenuhi kebutuhan penyusunan laporan ini, data yang dibutuhkan berupa data primer dan data sekunder. Pengumpulan data primer dengan cara mengukur langsung tingkat kebisingan dan pengambilan titik kordinat Global Positioning System (GPS) yang berada di unit Departemen Spare Part (DSP) maupun Departemen Las (DL). Sedangkan pada data sekunder berupa tata letak pabrik maupun jenis dan spesifikasin mesin yang berada di lokasi penelitian. 
Pengolah data yang dilakukan untuk mengetahui tingkat kebisingan pada unitDSPmaupun DL, menggunakan rumus dibawah ini :

a) Hitung range $(r)=\max -\min$

b) Hitung jumlah kelas $(k)=1+3,3 \log n$

c) Hitung interval kelas (i) $=r / k$

d) Hitung $\mathrm{L}_{\mathrm{eq}}=10 \log 1 / \mathrm{n} \sum \mathrm{Tn} \cdot 10^{0,1 \mathrm{Ln}}$; dimana $T_{n}$ adalah jumlah frekuensi sedangkan $L_{n}$ adalah nilai tengah

Selain mengukur langsung tingkat kebisingan yang dilakukan pada unit Departemen Spare Part dan Departemen Las, adapun waktu pengukuran yang digunakan untuk pengukuran kebisingan dikedua tempat pengukuran berdasarkan Keputusan Menteri Lingkungan Hidup KEP-48/MENLH/11/1996. Dalam metoda ini pengukuran tingkat kebisingan dilakukan selama 10 menit, dengan pembacaan dilakukan setiap 5 detik. Waktu pengukuran dilakukan selama aktivitas 7 jam dengan lokasi pengambilan sampel 2 titik pada Departemen Las dan 5 titik pada Departemen Spare Part dari jarak sumber bising yaitu 1,5 meter.

- L1 diambil mulai jam 08.00, mewakili jam 08.00-09.00

- L2 diambil mulai jam 09.00, mewakili jam 09.00-10.00

- L3 diambil mulai jam 10.00, mewakili jam 10.00-11.00

- L4 diambil mulai jam 11.00, mewakili jam $11.00-12.00$

- L5 diambil mulai jam 13.00, mewakili jam 13.00-14.00
- L6 diambil mulai jam 14.00, mewakili jam 14.00-15.00

- L7 diambilmulai jam 15.00, mewakili jam 15.00-16.00

L1- L7 merupakan simbol nama untuk pengambilan sampling kebisingan yang mewakili selama 7 jam kerja. Dalam penentuan titik sampling di PT. SA terdapat 5 titik sampling dengan masing-masing pengukuran selama 10 menit di DSP yang ditandai berwarna merah pada Gambar 2 sedangkan DL sendiri terdapat 2 titik sampling pada Gambar 3. Berikut penempatan titik sampling pada Gambar 2 dan Gambar 3.

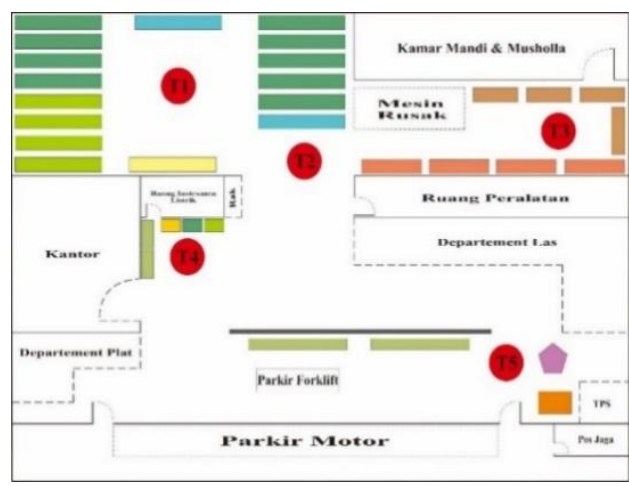

Gambar 2.

Titik Sampling Departemen Spare Part

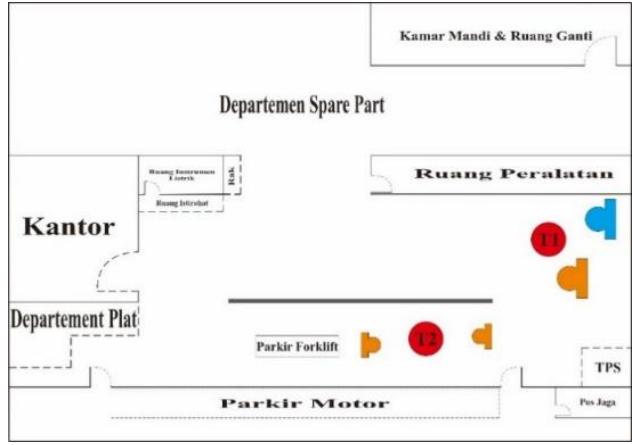

Gambar 3

Titik Sampling Departemen Las 


\subsection{Pola Sebaran Kebisingan}

Pola sebaran kebisingan digunakan untuk mengetahui dimana letak titik kebisingan tertinggi maupun terendah di Departemen Spare Part (DSP) dan Departemen Las (DL) dimulai dari hari senin sampai hari kamis. Untuk menampilkan pola sebaran kebisingan biasanya dibutuhkan titik Global Positioning System (GPS) tiap titik sampel (T1, T2 ,T3, T4 \& T5) yang diambil, beserta nilai intensitas kebisingan yang didapatkan dari hasil format peta 2D menggunakan aplikasi software Surfer 11 dengan metoda gridding kriging. Metoda kriging merupakan metoda default pada Surfer 11, metoda ini menghasilkan visual peta dari data yang tidak teratur menjadi data yang akurat pada jaringannya.

\section{HASIL DAN PEMBAHASAN}

\subsection{Data Hasil Pengukuran}

Adapun hasil contoh pengukuran nilai intensitas kebisingan pada hari senin jam 08.00-08.10 dengan rentang waktu jam 08.0009.00 di tempat Departemen Spare Part (DSP) titik sampel (T1) dengan jumlahdata 120 , dapat dilihat Tabel 1 (lampiran). Pada tabel tersebut akan dihitung dan mendapatkan nilai jumlah data (n), nilai maksimum (Max), nilai minimum (Min), nilai range (R), nilai jumlah kelas (k), nilai interval kelas (i) maupun nilai Leq. Berikut hasil contoh pengukuran perhitungan rumus di atas sebagai berikut :
a) Jumlah Data $(\mathrm{n}) \quad=120$
b) Nilai Maksimum (Max) $=93,5$
c) Nilai Minimum (Min) $=67,6$
d) Nilai Range $(R)=\operatorname{Max}-$ Min

$$
\begin{aligned}
& =93,5-67,6 \\
& =25,9
\end{aligned}
$$

e) Hitung Jumlah Kelas (k)

$$
\begin{aligned}
& =1+3,3 \log n \\
& =1+3,3 \log (120) \\
& =7,86 \sim 8
\end{aligned}
$$

f) Hitung interval kelas (i)

$$
\begin{aligned}
& =r / k \\
& =25,9 / 8 \\
& =3,28 \sim 3
\end{aligned}
$$

Setelah menghitung nilai range $(\mathrm{R})$, nilai jumlah kelas (k) dan nilai interval kelas (i), lalu dibuat tabel distribusi frekuensinya dan mengitung nilai frekuensi Leq Kebisingan.

Tabel 1. Distribusi Frekuensi Intensitas Kebisingan Titik 1 DSP (dB)

\begin{tabular}{ccccc}
\hline No & $\begin{array}{c}\text { Interval } \\
\text { Bising }\end{array}$ & $\begin{array}{c}\text { Nilai } \\
\text { Tengah }\end{array}$ & Frekuensi \\
\hline 1 & 66 & 69 & 67,5 & 4 \\
\hline 2 & 70 & 73 & 71,5 & 38 \\
\hline 3 & 74 & 77 & 75,5 & 22 \\
\hline 4 & 78 & 81 & 79,5 & 32 \\
\hline 5 & 82 & 85 & 83,5 & 16 \\
\hline 6 & 86 & 89 & 87,5 & 3 \\
\hline 7 & 90 & 93 & 91,5 & 5 \\
\hline 8 & 94 & 97 & 95,5 & 0 \\
\hline \multicolumn{5}{c}{ Jumlah } \\
\hline \multicolumn{5}{c}{} \\
\hline
\end{tabular}

Hasil dari Tabel 1, distribusi frekuensi intensitas kebisingan yang sudah dikategori berdasarkan interval bisingnya, dapat ditunjukan pada rentang waktu 66-69 dB, 70$73 \mathrm{~dB}, 74-77 \mathrm{~dB}$ dan 78-81 dB berada pada posisi dominan dikarenakan kondisi mesin saat itu hanya sebagian beroperasi dan pembuatan produksi nya hanya sedikit. Sedangkan rentang waktu pada interval bising 82-85 dB dan 86-89 dB berada posisi yang 
bukan dominan dikarenakan mesin beroperasi secara bergantian atau hanya sebagian saja, getaran dan melebihi nilai ambang batas kebisingan. Sedangkan rentang waktu pada interval bising 90-93 dB melebihi nilai ambang batas, hal ini dipengaruhi kondisi mesin yang beroperasi, getaran, pengeras suara (sound speaker) maupun pelonggaran alat mesin tersebut jika terasa macet dengan cara dipukul. Diperoleh bahwa selain suara mesin, suara yang ditimbulkan oleh kegiatan manusia juga kadang menimbulkan kebisingan [4].

g) Hitung $L_{e q}$

$$
\begin{aligned}
= & 10 \log 1 / \mathrm{n} \sum \operatorname{Tn} .10^{0,1 \mathrm{Ln}} \\
= & 10 \log 1 / 120 \\
& \left(4^{*} 10^{\wedge}\left(0,1^{*} 67,5\right)+\left(38^{*} 10^{\wedge}\left(0,1^{\star} 71,5\right)+. .\right.\right. \\
& \ldots . \mathrm{Tn})) \\
= & 81,4 \mathrm{~dB}
\end{aligned}
$$

Hasil perhitungan nilai Leq di atas, maka bisa dilihat Tabel 2.2 Leq total intensitas kebisingan hari senin. Leq total dijumlahkan dari titik sampel (T1) L1 jam 08.00-09.00 sampai dengan titik sampel (T5) L7 jam 15.0016.00 , yang sebelumnya data 120 tersebut terpisah.

Tabel 2. Leq Total Intensitas Kebisingan Hari Senin DSP

\begin{tabular}{cccccc}
\hline \multirow{2}{*}{ No } & \multicolumn{5}{c}{ Titik Sampel (dB) } \\
\cline { 2 - 6 } & T1 & T2 & T3 & T4 & T5 \\
\hline 1 & 81,4 & 81 & 79,6 & 83,1 & 87,9 \\
\hline 2 & 72,7 & 80,7 & 80,3 & 80,8 & 86,1 \\
\hline 3 & 87,3 & 87,5 & 86,7 & 86,9 & 88,2 \\
\hline 4 & 87,6 & 85,8 & 86,6 & 82,3 & 82,7 \\
\hline 5 & 86,9 & 84,7 & 87,1 & 90,1 & 84,0 \\
\hline 6 & 85,5 & 85,7 & 90,8 & 90,1 & 87,9 \\
\hline 7 & 90,2 & 88,6 & 88,5 & 84,5 & 91,5 \\
\hline Leq & 84,5 & 84,9 & 85,6 & 85,4 & 86,9 \\
Total & & & & & \\
\hline
\end{tabular}

Sedangkan pada Tabel 2 hasil contoh pengukuran nilai intensitas kebisingan pada hari senin jam 08.00 - 08.10 dengan rentang waktu jam 08.00 - 09.00 di tempat Departemen Las (DL) titik sampel (T1) dengan jumlah data 120, dapat dilihat Tabel 2 (lampiran). Pada Tabel tersebut akan dihitung dan mendapatkan nilai jumlah data (n), nilai maksimum (Max), nilai minimum (Min), nilai range $(R)$, nilai nilai jumlah kelas $(k)$, nilai interval kelas (i) maupun nilai Leq. Adapun rumus perhitungan yang dapat dilihat bagian bawah ini :
a) Jumlah Data (n) $=120$
b) Nilai Maksimum (Max) $=97,5$
C) Nilai Minimum (Min) $=80,8$
d) Nilai Range $(\mathrm{R})=\mathrm{Max}-\mathrm{Min}$

$$
\begin{aligned}
& =9,5-80,8 \\
& =16,7
\end{aligned}
$$

e) Hitung Jumlah Kelas (k)

$$
\begin{aligned}
& =1+3,3 \log n \\
& =1+3,3 \log (120) \\
& =7,86 \sim 8
\end{aligned}
$$

f) Hitung interval kelas (i)

$$
\begin{aligned}
& =r / k \\
& =16,7 / 8 \\
& =2,2 \sim 2
\end{aligned}
$$

Setelah menghitung nilai range $(R)$, nilai jumlah kelas (k) dan nilai interval kelas (i), lalu dibuat tabel distribusi frekuensinya dan mengitung nilai frekuensi Leq Kebisingan. 
Tabel 3. Distribusi Frekuensi Intensitas Kebisingan Titik 1 DL (dB)

\begin{tabular}{ccccc}
\hline No & \multicolumn{2}{c}{$\begin{array}{c}\text { Interval } \\
\text { Bising }\end{array}$} & $\begin{array}{c}\text { Nilai } \\
\text { Tengah }\end{array}$ & Frekuensi \\
\hline 1 & 79 & 81 & 80 & 1 \\
\hline 2 & 82 & 84 & 83 & 11 \\
\hline 3 & 85 & 87 & 86 & 18 \\
\hline 4 & 88 & 90 & 89 & 32 \\
\hline 5 & 91 & 93 & 92 & 41 \\
\hline 6 & 94 & 96 & 95 & 13 \\
\hline 7 & 97 & 99 & 98 & 4 \\
\hline 8 & 100 & 102 & 101 & 0 \\
\hline \multicolumn{5}{c}{ Jumlah } \\
\hline \multicolumn{5}{c}{}
\end{tabular}

Hasil dari Tabel 3. Distribusi frekuensi intensitas kebisingan yang sudah dikategori berdasarkan interval bisingnya, dapat ditunjukan pada rentang waktu 91-93 dB, 88$90 \mathrm{~dB}, 85-87 \mathrm{~dB}$ dan 94-96 dB berada pada posisi dominan dikarenakan dipengaruhi mesin gerinda yang sedang beroperasi dalam pemotong maupun finshing perataan tabung silinder dan lainnya. Sedangkan rentang waktu pada interval bising 79-81 dB dan 82-84 $\mathrm{dB}$ berada posisi yang bukan dominan hal disebabkan karena mesin gerinda yang satu dengan yang lain beroperasi dengan jarak yang jauh, jika mesin gerinda satu kondisi nyala maka yang sebelah mati atau pun sebaliknya bisa juga kondisi mesin gerinda nyala bersamaan. Sedangkan rentang waktu pada interval bising 97-99 dB hal ini dipengaruhi kondisi mesin gerinda digabung dengan jatuhnya lembaran plat yang jatuh dari Departemen Plat, pemukulan benda supaya rata maupun finishing dan faktor lainnya.

g) Hitung $L_{e q}$ $=10 \log 1 / \mathrm{n} \sum \operatorname{Tn} \cdot 10^{0,1 \mathrm{Ln}}$

$$
\begin{aligned}
& =10 \log 1 / 120 \\
& \left(1 * 10^{\wedge}\left(0,1^{\star} 80\right)+\left(11^{*} 10^{\wedge}\left(0,1^{\star} 83\right)+. . \mathrm{Tn}\right)\right) \\
& =91,4 \mathrm{~dB}
\end{aligned}
$$

Hasil perhitungan nilai Leq di atas, maka bisa dilihat Tabel 4 Leq total intensitas kebisingan hari senin. Leq total dijumlahkan dari titik sampel (T1) L1 jam 08.00-09.00 sampai dengan titiksampel (T5) L7 jam 15.00-16.00, yang sebelumnya data 120 tersebut terpisah.

Tabel 4. Leq Total Intensitas Kebisingan Hari Senin DL

\begin{tabular}{ccc}
\hline \multirow{2}{*}{ No } & \multicolumn{2}{c}{ Titik Sampel (dB) } \\
\cline { 2 - 3 } & T1 & T2 \\
\hline $\mathbf{1}$ & 91,4 & 90 \\
\hline $\mathbf{2}$ & 89,9 & 92,5 \\
\hline $\mathbf{3}$ & 91,4 & 90,0 \\
\hline $\mathbf{4}$ & 91,1 & 90,9 \\
\hline $\mathbf{5}$ & 91,4 & 90,2 \\
\hline $\mathbf{6}$ & 91,8 & 89,7 \\
\hline $\mathbf{7}$ & 89,1 & 92,9 \\
\hline Leq Total & 90,9 & 91,0 \\
\hline
\end{tabular}

\subsection{Analisa Pola Sebaran Kebisingan}

\subsubsection{Departemen Spare Part (DSP)}

Pada unit Departemen Spare Part (DSP) tingkat kebisingan pada hari rabu telah melebihi Nilai Ambang Batas (NAB) sebesar $92 \mathrm{~dB}$ pada titik tertinggi, dimana nilai ambang batas kebisingannya sebesar $85 \mathrm{~dB}$. Faktor tersebut dipengaruhi oleh getaran mesin yang dihasilkan, suara kipas, berdekatan dengan mesin gerinda dan mesin las maupun pemasangan bahan dan pengendoran mesin yang macet dengan cara dipukul sampai terasa longgar. Sedangkan nilai intensitas kebisingan terendah pada hari senin sebesar 84,5 dB dan tidak melebihi ambang batas. Dimana pada hari tersebut mesin gerinda 
keadaan mati (OFF) dan mesin las saja yang beroperasi. Pada Tabel 2.5 dan Gambar 2.3 dapat dilihat perbandingan nilai Leq kebisingan beserta pola sebaran kebisingan dari hari senin sampai dengan hari kamis di Departemen Spare Part.

Tabel 5. PerbandinganLeq Intensitas Kebisingan Hari Senin - Kamis DSP

\begin{tabular}{ccc}
\hline \multicolumn{3}{c}{ Departemen Spare Part } \\
\hline Hari/Titik & $\begin{array}{c}\text { Tertinggi } \\
\text { (dB) }\end{array}$ & $\begin{array}{c}\text { Terendah } \\
\text { (dB) }\end{array}$ \\
\hline Senin & 86,9 & 84,5 \\
\hline Selasa & 90,1 & 87,8 \\
\hline Rabu & 92 & 86,5 \\
\hline Kamis & 90,3 & 86,9 \\
\hline
\end{tabular}

Dapat dilihat pada Tabel 5 Perbandingan Leq intensitas kebisingan dari senin sampai dengan kamis di DSP, bahwa nilai intensitas kebisingan tertinggi pada hari rabu sebesar 92 $\mathrm{dB}$ dan telah melewati nilai ambang batas kebisingan. Sedangkan nilai intensitas terendah pada hari senin sebesar $84,5 \mathrm{~dB}$ dan tidak melewati nilai ambang batas kebisingan $85 \mathrm{~dB}$ di ruang unit DSP.

\subsubsection{Departemen Las (DL)}

Pada unit Departemen Las (DL) tingkat kebisingan pada hari rabu telah melebihi Nilai Ambang Batas (NAB) sebesar $92 \mathrm{~dB}$ pada titik tertinggi, dimana nilai ambang batas kebisingannya sebesar $85 \mathrm{~dB}$. Faktor tersebut dipengaruhi oleh suara kipas, mesin gerinda dan mesin las maupun pemukulan bahan yang diratakan beserta finishing. Sedangkan nilai intensitas kebisingan terendah pada hari senin sebesar 86,9 dB dan melebihi ambang batas. Dimana pada hari tersebut mesin gerinda kondisi sebagian mati (OFF) dan mesin las saja yang beroperasi. Adapun faktor lain yang dapat mempengaruhi yaitu mesin gerinda yang kadang sering berpindah tempat karena terbatasnya ruang yang begitu sempit dan padat dalam pengerjaan, lalu lalang truk forklift yang membawa lembaran plat untuk di tekuk, potong maupun pembuatan tabung silender. Pada Tabel 2.6 dan Gambar 2.4 dapat dilihat perbandingan nilai Leq kebisingan beserta pola sebaran kebisingan, dari hari senin sampai dengan hari kamis di Departemen Las.

Tabel 6. PerbandinganLeq Intensitas Kebisingan Hari Senin - Kamis DL

\begin{tabular}{ccc}
\hline \multicolumn{3}{c}{ Departemen Las } \\
\hline Hari/Titik & $\begin{array}{c}\text { Tertinggi } \\
\text { (dB) }\end{array}$ & $\begin{array}{c}\text { Terendah } \\
\text { (dB) }\end{array}$ \\
\hline Senin & 90,9 & 86,9 \\
\hline Selasa & 90,1 & 88,8 \\
\hline Rabu & 92 & 89,9 \\
\hline Kamis & 90,3 & 89,5 \\
\hline
\end{tabular}

Dapat dilihat pada Tabel 6, perbandingan Leq intensitas kebisingan dari senin sampai dengan kamis di DL, bahwa nilai intensitas kebisingan tertinggi pada hari rabusebesar 92 $\mathrm{dB}$ dan telah melewati nilai ambang batas kebisingan $85 \mathrm{~dB}$. Sedangkan nilai intensitas kebisingan terendah pada hari senin sebesar 86,9 dB dan melewati nilai ambang batas kebisingan di ruang unit DL. 


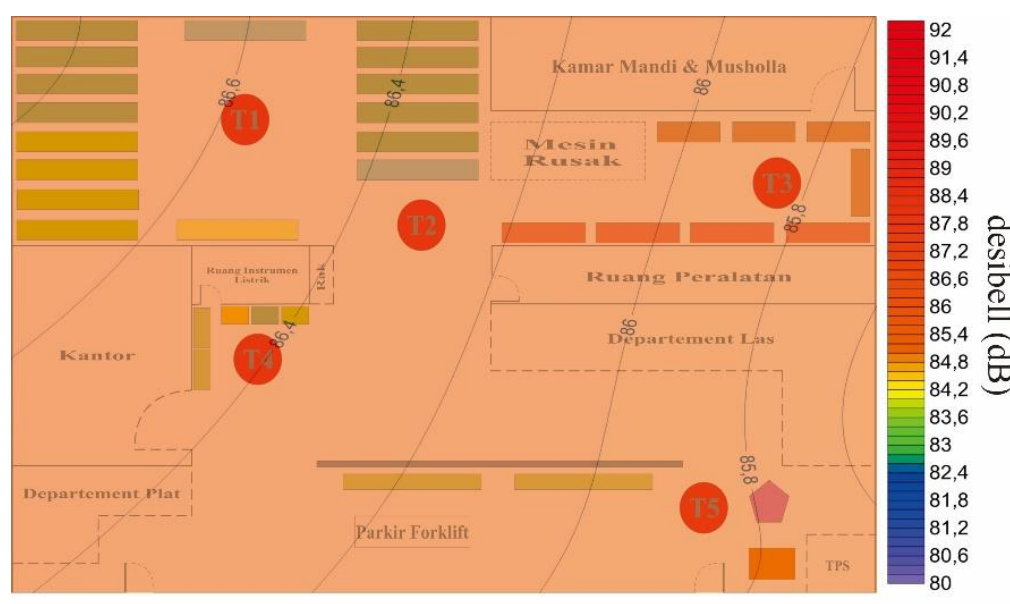

Hari Senin - DSP

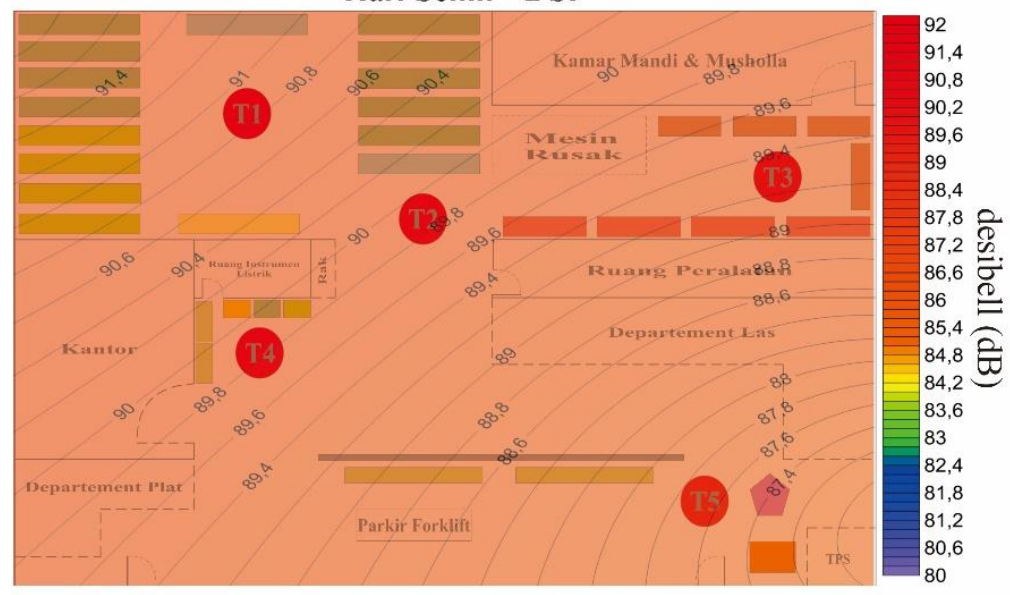

Hari Rabu - DSP

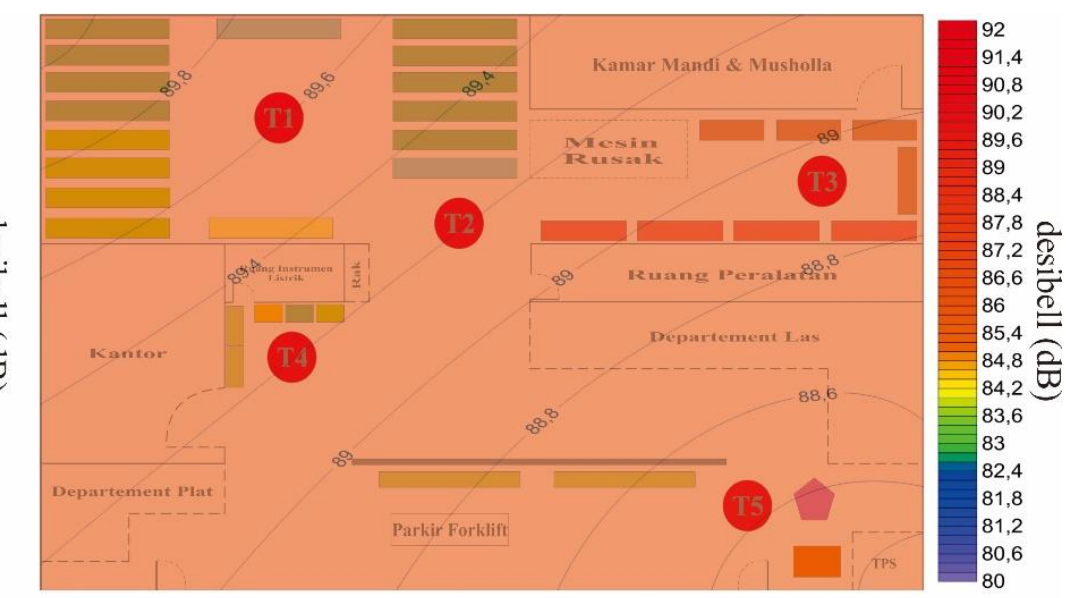

Hari Selasa - DSP

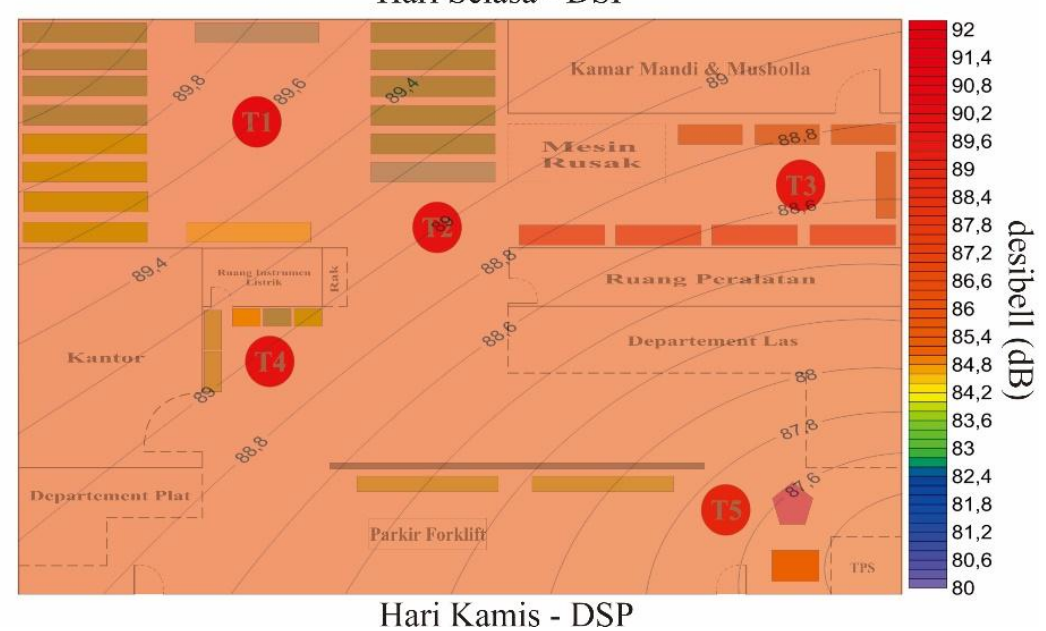

Hari Kamis - DSP

Gambar 4. 
Pemetaan Kebisingan di Ruang Departemen Spare Part dan Departemen Las menggunakan Aplikasi Surfer

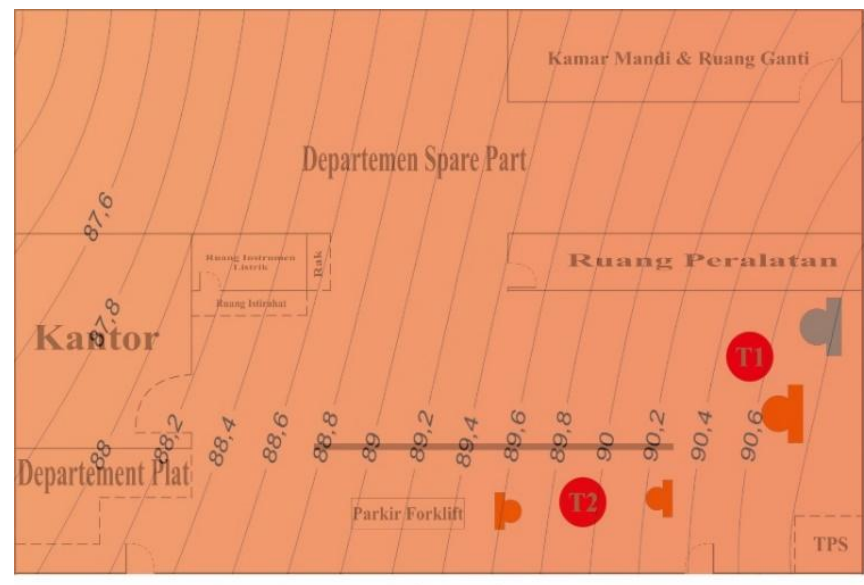

Hari Senin - DL

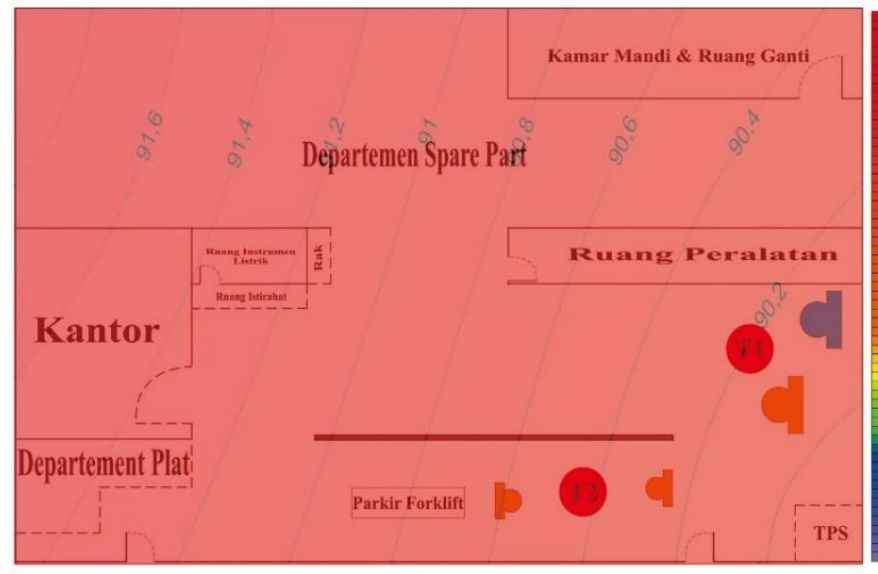

Hari Rabu - DL

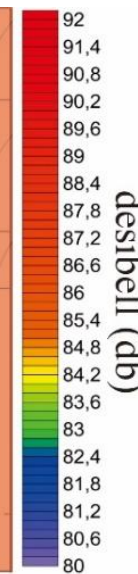

92
91,4
90,8
90,2
89,6
89
88,4
87,8
87,2
86,6
86
86
85,4
84,8
84,2
83,6
83
82,4
81,8
81,2
80,6
80

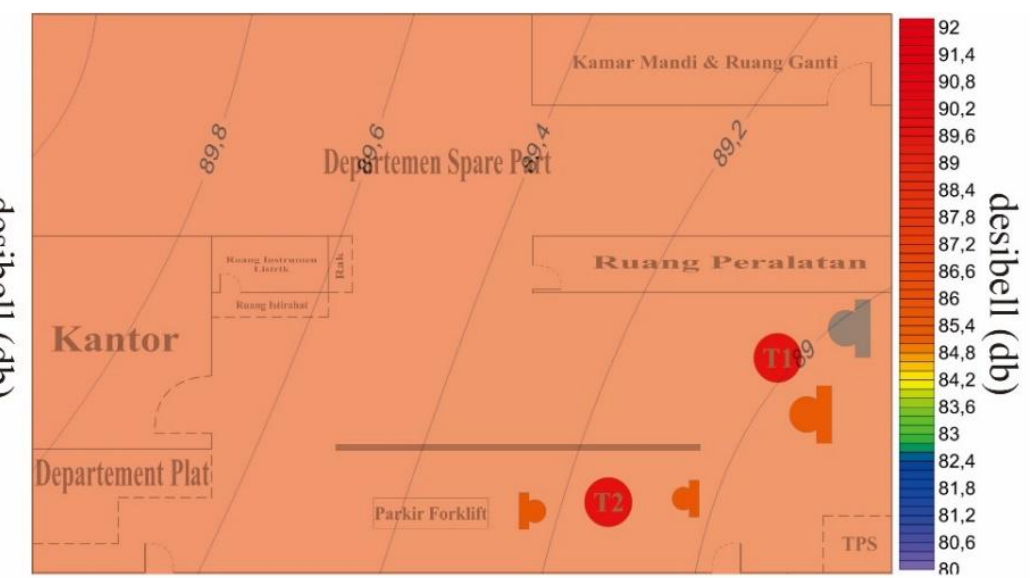

Hari Selasa - DL

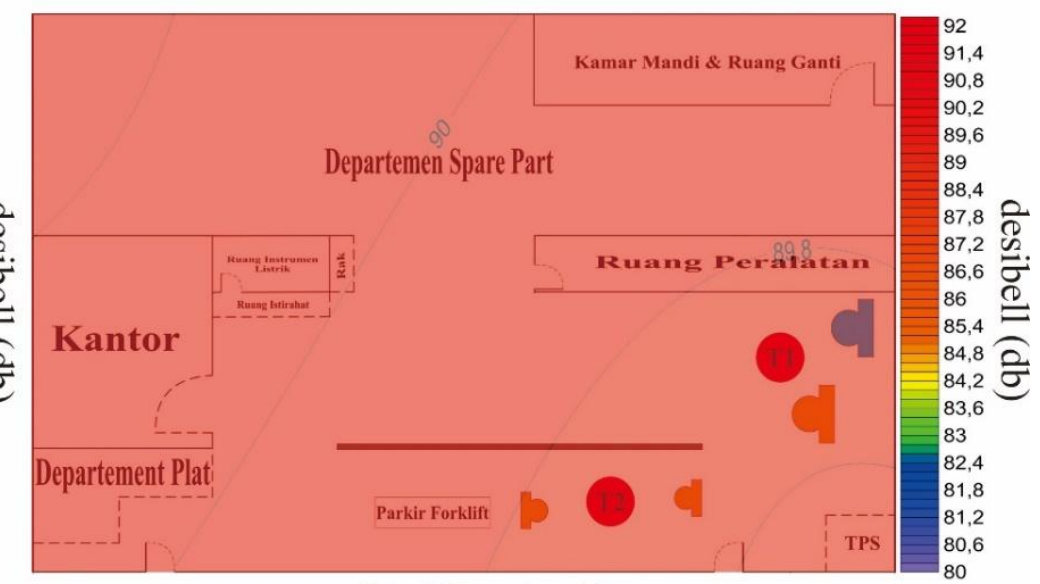

Hari Kamis - DL

Gambar 5.

Pola Sebaran Intensitas Kebisingan Hari Senin - Kamis Departemen Las 


\section{KESIMPULAN}

Penelitian kebisingan di PT. SA pada ruang Departemen Spare Part (DSP) dan Departemen Las (DL) menunjukkan bahwa:

- $\quad$ Tingkat kebisingan yang tertinggi yaitu 92 $\mathrm{dB}$ diman nilai tersebut telah melebihi ambang batas yang sudah ditetapkan yaitu $85 \mathrm{~dB}$ selama waktu 8 jam. Adapun pada DSP mempunyai posisi tingkat kebisingan terendah dibawah unit DL sebesar 84,5 dB dan melebihi nilai ambang batas yang sudah ditetapkan 85 dB selama waktu 8 jam.

- Perbandingan nilai Leq total pada unit DSP dan DL dari hari senin sampai kamis. Pada unit DSP nilai Leq tertinggi pada hari rabu dengan nilai rentang intensitas kebisingan 90,8 - 91dB. Sedangkan pada unit DL nilai Leq tertinggi pada hari rabu dengan nilai intensitas kebisingan 90,4 dB.

- Jenis kebisingan yang berada pada unit Departemen Spare Part adalah kebisingan kontinu sedangkan pada Departemen Las adalah kebisingan terputus-putus (non kontinu).

\section{DAFTAR PUSTAKA}

[1] Wahyuni, S., Yustiani, Y., Juliandahri, A. "Analisis Tingkat Kebisingan Lalu Lintas di Jalan Cihampelas dan Jalan Sukajadi Kota
Bandung," Journal of Community Based Environmental Engineering and Management, vol. 2, no.1, pp. 9-12, 2018.

[2] Khairai, K.M., Salleh, N.S., Yusoff, A.R. "Occupational Noise Reduction in CNC Stripping Process," IOP Conference Series, Materials Science and Engineering, 319, 012034, 2018.

[3] Mohammadizadeh, M., Ahmadi, S.H., Sekhavati, E., Ahani-Jegar, K. "Noise Pollution Effect in Flour Factory on Workers' Hearing in Lamerd City," Journal of Medicine and Life, vol. 8, special issue 3, pp. 208-211, 2015.

[4] Mulyatna, L., Rusmaya, D., Baehaki, D. "Hubungan Kebisingan dengan Persepsi Masyarakat di Ruang Rawat Inap Rumah Sakit kelas A, Kelas B, dan Kelas C di Kota Bandung," Journal of Community Based Environmental Engineering and Management, vol. 1, no. 1, pp. 25-31, 2017.

[5] Zulfiar, F. "Analisis Variasi Roda Gerinda terhadap Tingkat Kebisingan Mesin Gerinda Sudut Maktec MT 90 pada Hasil Pengelasan 1 G," Jurnal Teknik Mesin, vol. 4, no. 1, pp. 1-8, 2015.

[6] Setyaningrum, I., Widjasena, B., Suroto. "Analisa Pengendalian Kebisingan Pada Penggerindaan Di Area Fabrikasi Perusahaan Pertambangan," Jurnal Kesehatan Masyarakat, Vol 2, No 4. 2014 